\title{
ERRATUM
}

Adv Exp Med Biol - Advances in Microbiology, Infectious Diseases and Public Health DOI 10.1007/5584_2017_16

(C) Springer International Publishing Switzerland 2017

\section{Emerging Zika Virus Infection: A Rapidly Evolving Situation}

\author{
Licia Bordi, Tatjana Avsic-Zupanc, Eleonora Lalle, \\ Francesco Vairo, Maria Rosaria Capobianchi, \\ and Pedro Fernando da Costa Vasconcelos
}

Author's names were initially listed incorrectly which has been corrected in this version as Licia Bordi, Tatjana Avsic-Zupanc, Eleonora Lalle, Francesco Vairo, Maria Rosaria Capobianchi. 